\title{
Influence of Oligonucleotide Grafting Density on \\ Surface-Mediated DNA Transport and Hybridization
}

\section{Supporting Information}

Jeremiah C. Traeger, Zachary Lamberty, and Daniel K. Schwartz*

Department of Chemical and Biological Engineering

University of Colorado Boulder, Boulder, Colorado 80309

*Address correspondence to daniel.schwartz@colorado.edu 


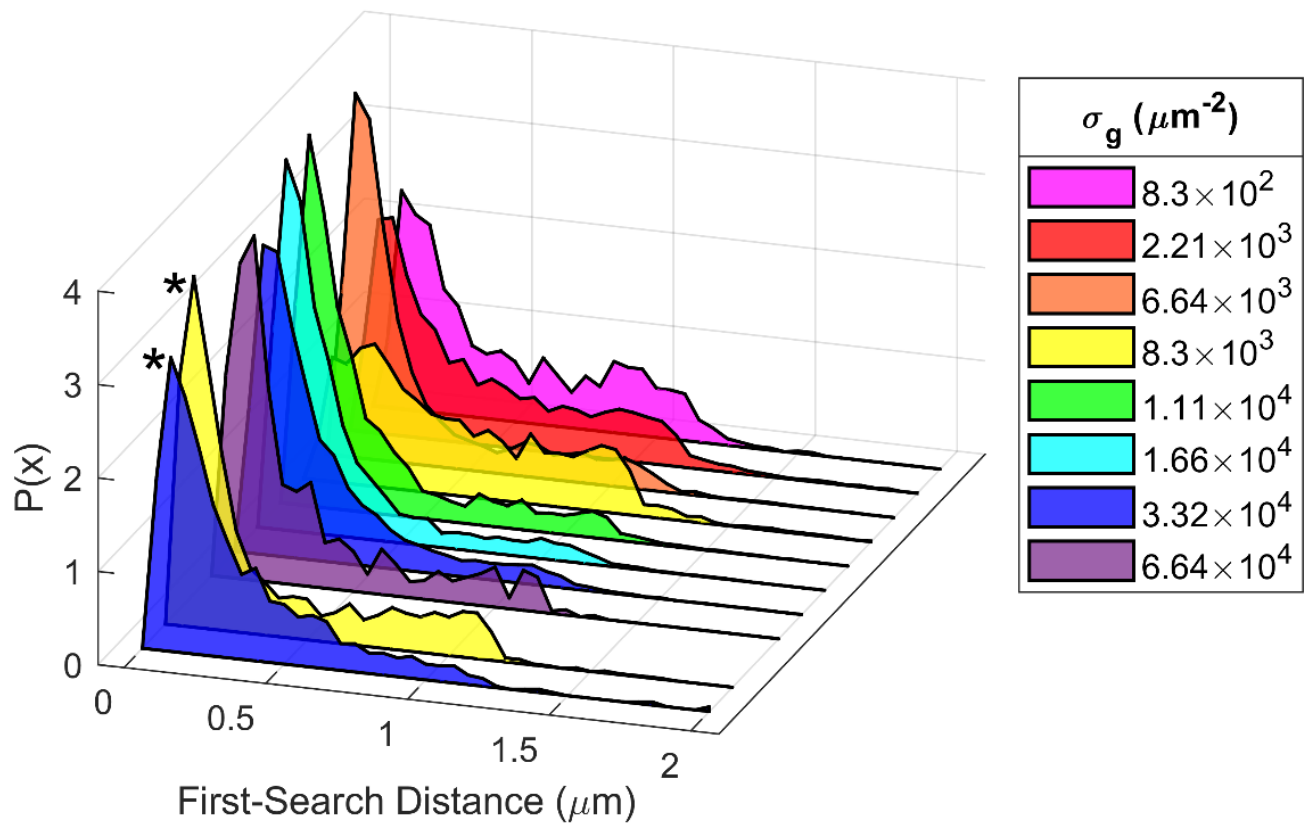

Figure S1: First-Search Distance probability densities as a function of $\sigma_{g}$. Distributions marked with an asterisk $(*)$ refer to experiments with noncomplementary DNA.
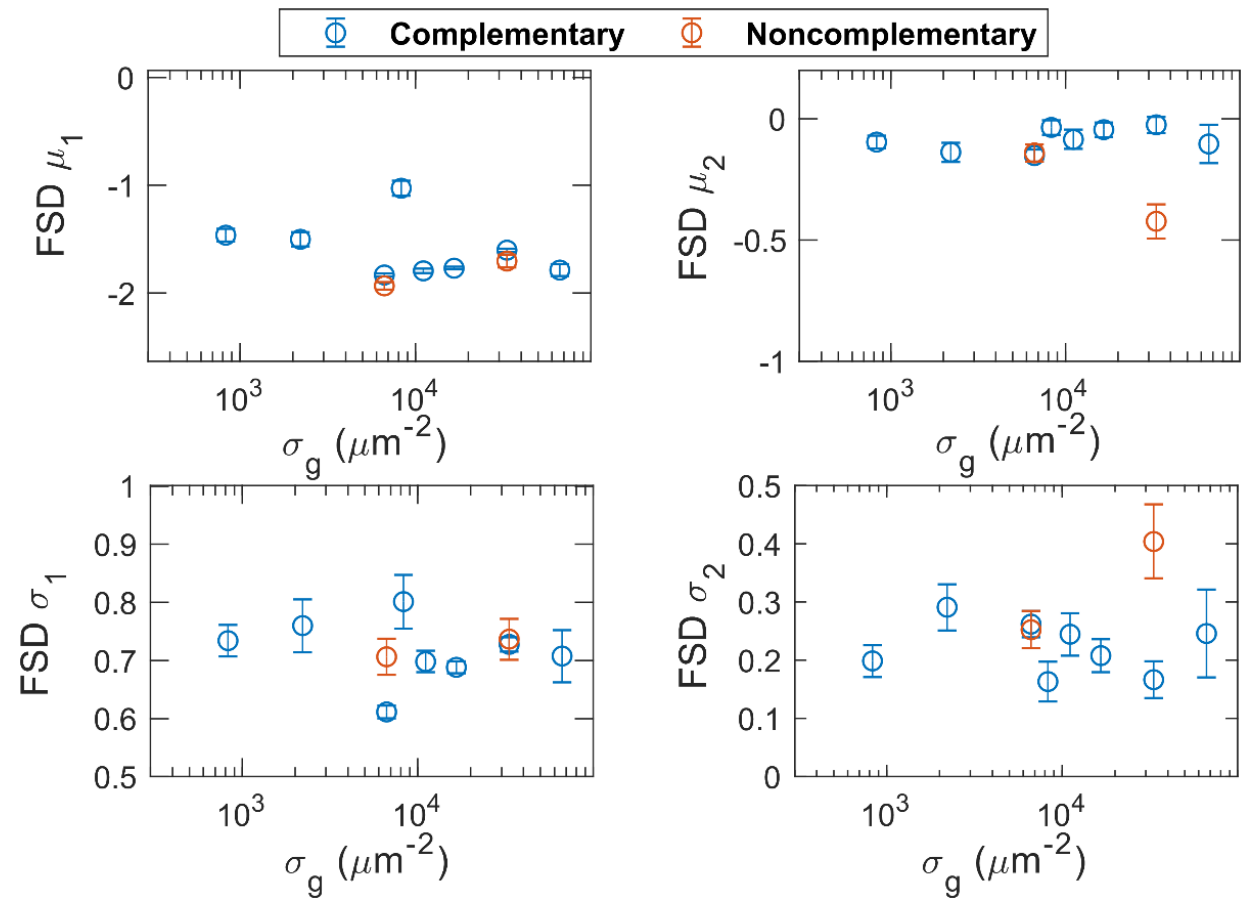

Figure S2: First-Search Distance PDF fit parameters for a bimodal mixed lognormal function. $P(x)=\left(\frac{1}{\sqrt{2 \pi} \sigma_{1} x}\right) e^{-\frac{(\ln (x)-\mu)^{2}}{2 \sigma^{2}}}$, where $\mu_{i}$ is the location parameter for lognormal mode $\mathrm{i}$, and $\sigma_{i}$ is the shape parameter for lognormal mode $\mathrm{i}$. Mode 1 corresponds to the shorter search-distance population, while mode 2 corresponds with the longer search-distance population. 


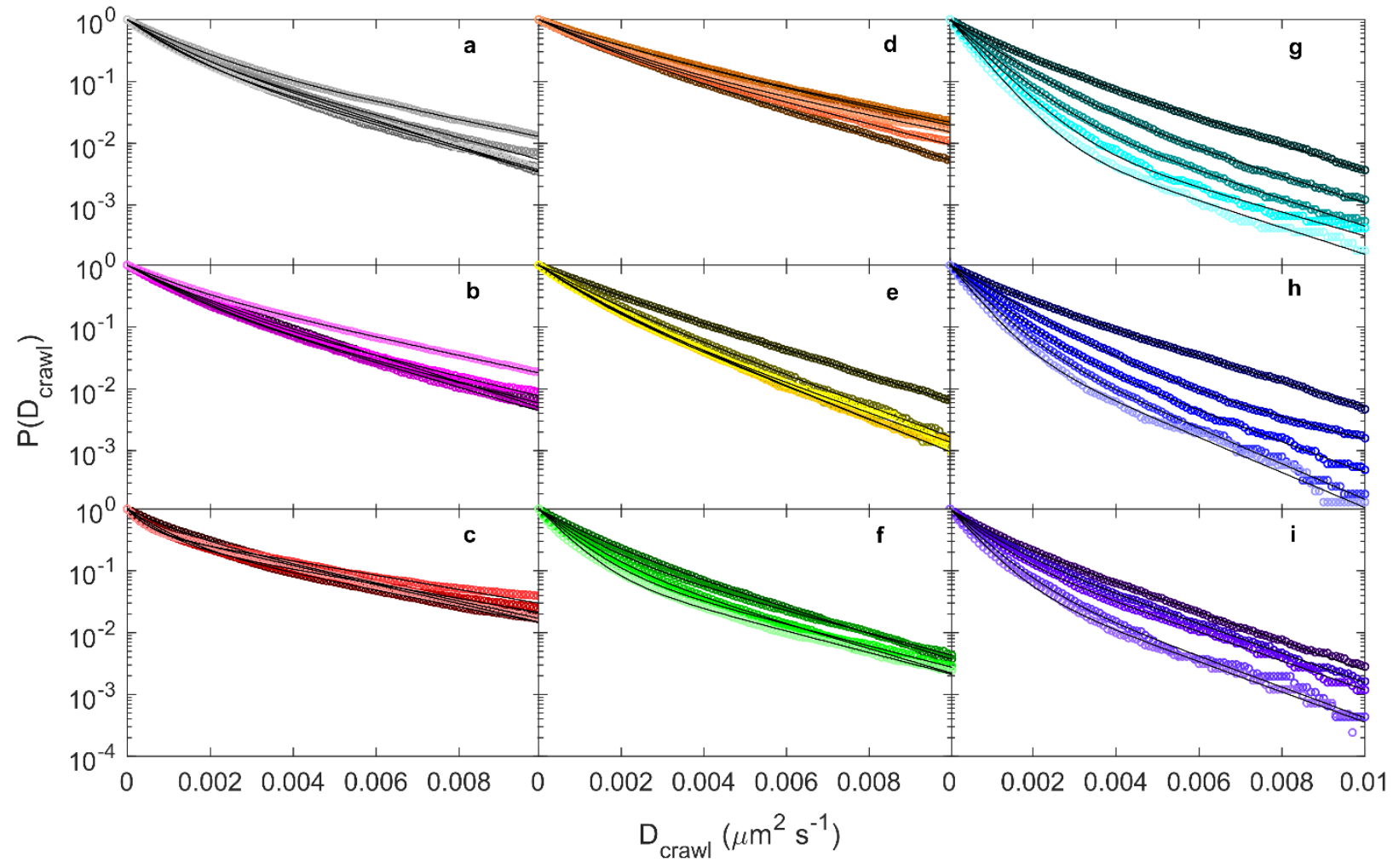

Figure S3: Complementary cumulative distributions, $P\left(D_{\text {crawl }}\right)$, for waiting time diffusion coefficients as a function of grafting density. Dark colors indicate short waiting time, lighter colors indicate longer waiting time. Black lines are biexponential fit distributions. (a) $\sigma_{g}=$ $0 \mu \mathrm{m}^{-2}$ (OEG surface). (b) $\sigma_{g}=8.3 \times 10^{2} \mu \mathrm{m}^{-2}$ (c) $\sigma_{g}=2.2 \times 10^{3} \mu \mathrm{m}^{-2}$ (d) $\sigma_{g}=$ $6.6 \times 10^{3} \mu \mathrm{m}^{-2}$ (e) $\sigma_{g}=8.3 \times 10^{3} \mu \mathrm{m}^{-2}$ (f) $\sigma_{g}=1.1 \times 10^{4} \mu \mathrm{m}^{-2}$ (g) $\sigma_{g}=$ $1.6 \times 10^{4} \mu m^{-2}$ (h) $\sigma_{g}=3.3 \times 10^{4} \mu m^{-2}$ (i) $\sigma_{g}=6.6 \times 10^{4} \mu m^{-2}$. 
Table S1: Biexponential fit values for wait-time diffusion coefficients. Values in parentheses indicate uncertainty in the last digit. $\mathrm{D}_{1}$ is the diffusion coefficient corresponding with slower crawling diffusion. $f_{1}$ is the relative population fraction of slower crawling diffusion. $\mathrm{D}_{2}$ is the diffusion coefficient corresponding with faster diffusion.

\begin{tabular}{|c|c|c|c|c|c|c|}
\hline \multirow{2}{*}{$\sigma_{g}\left(\mu m^{2} s^{-1}\right)$} & & \multicolumn{5}{|c|}{$T_{w}(s)$} \\
\hline & & 0.2 & 0.3 & 0.4 & 0.5 & 0.6 \\
\hline 0 & $\begin{array}{c}f_{1} \\
D_{1}\left(\mu m^{2} s^{-1}\right) \\
D_{2}\left(\mu m^{2} s^{-1}\right) \\
\end{array}$ & $\begin{array}{l}0.56(1) \\
0.00079(2) \\
0.00203(5) \\
\end{array}$ & $\begin{array}{l}0.73(2) \\
0.00084(3) \\
0.00228(6) \\
\end{array}$ & $\begin{array}{l}0.66(2) \\
0.00084(3) \\
0.00249(6) \\
\end{array}$ & $\begin{array}{l}0.68(2) \\
0.00107(2) \\
0.00309(7) \\
\end{array}$ & $\begin{array}{l}0.67(1) \\
0.00072(2) \\
0.00221(3) \\
\end{array}$ \\
\hline 830 & $\begin{array}{c}f_{1} \\
D_{1}\left(\mu m^{2} s^{-1}\right) \\
D_{2}\left(\mu m^{2} s^{-1}\right)\end{array}$ & $\begin{array}{l}0.36(1) \\
0.00077(3) \\
0.00205(1) \\
\end{array}$ & $\begin{array}{l}0.73(2) \\
0.00104(3) \\
0.00259(9) \\
\end{array}$ & $\begin{array}{l}0.60(2) \\
0.00086(2) \\
0.00220(4) \\
\end{array}$ & $\begin{array}{l}0.71(3) \\
0.00107(3) \\
0.00272(9) \\
\end{array}$ & $\begin{array}{l}0.50(1) \\
0.00107(2) \\
0.00299(3)\end{array}$ \\
\hline 2200 & $\begin{array}{c}f_{1} \\
D_{1}\left(\mu m^{2} s^{-1}\right) \\
D_{2}\left(\mu m^{2} s^{-1}\right) \\
\end{array}$ & $\begin{array}{l}0.53(2) \\
0.00093(4) \\
0.00300(6) \\
\end{array}$ & $\begin{array}{l}0.69(1) \\
0.00077(2) \\
0.00325(8) \\
\end{array}$ & $\begin{array}{l}0.69(2) \\
0.00063(3) \\
0.0037(1) \\
\end{array}$ & $\begin{array}{l}0.58(1) \\
0.00040(3) \\
0.0038(1) \\
\end{array}$ & $\begin{array}{l}0.495(6) \\
0.00034(1) \\
0.00281(2) \\
\end{array}$ \\
\hline 6600 & $\begin{array}{c}f_{1} \\
D_{1}\left(\mu m^{2} s^{-1}\right) \\
D_{2}\left(\mu m^{2} s^{-1}\right) \\
\end{array}$ & $\begin{array}{l}0.45(2) \\
0.00093(3) \\
0.00215(2) \\
\end{array}$ & $\begin{array}{l}0.54(5) \\
0.00145(8) \\
0.0031(1) \\
\end{array}$ & $\begin{array}{l}0.65(3) \\
0.00158(5) \\
0.0036(1) \\
\end{array}$ & $\begin{array}{l}0.61(3) \\
0.00114(5) \\
0.00272(6) \\
\end{array}$ & $\begin{array}{l}0.76(2) \\
0.00138(4) \\
0.0037(1) \\
\end{array}$ \\
\hline 8300 & $\begin{array}{c}f_{1} \\
D_{1}\left(\mu m^{2} s^{-1}\right) \\
D_{2}\left(\mu m^{2} s^{-1}\right) \\
\end{array}$ & $\begin{array}{l}0.30(3) \\
0.00104(5) \\
0.00212(2) \\
\end{array}$ & $\begin{array}{l}0.48(3) \\
0.00087(3) \\
0.00173(2) \\
\end{array}$ & $\begin{array}{l}0.56(2) \\
0.00079(2) \\
0.00163(2) \\
\end{array}$ & $\begin{array}{l}0.58(2) \\
0.00072(2) \\
0.00164(3) \\
\end{array}$ & $\begin{array}{l}0.65(3) \\
0.00080(2) \\
0.00180(4)\end{array}$ \\
\hline 11000 & $\begin{array}{c}f_{1} \\
D_{1}\left(\mu m^{2} s^{-1}\right) \\
D_{2}\left(\mu m^{2} s^{-1}\right)\end{array}$ & $\begin{array}{l}0.57(2) \\
0.00090(2) \\
0.00210(2) \\
\end{array}$ & $\begin{array}{l}0.74(1) \\
0.00084(2) \\
0.00244(4) \\
\end{array}$ & $\begin{array}{l}0.78(1) \\
0.00074(2) \\
0.00218(4) \\
\end{array}$ & $\begin{array}{l}0.852(9) \\
0.00068(2) \\
0.00251(5) \\
\end{array}$ & $\begin{array}{l}0.883(8) \\
0.00060(2) \\
0.00250(6)\end{array}$ \\
\hline 16000 & $\begin{array}{c}f_{1} \\
D_{1}\left(\mu m^{2} s^{-1}\right) \\
D_{2}\left(\mu m^{2} s^{-1}\right) \\
\end{array}$ & $\begin{array}{l}0.51(3) \\
0.00088(3) \\
0.00203(3) \\
\end{array}$ & $\begin{array}{l}0.87(2) \\
0.00089(2) \\
0.00210(7) \\
\end{array}$ & $\begin{array}{l}0.929(7) \\
0.00071(1) \\
0.00198(5) \\
\end{array}$ & $\begin{array}{l}0.974(5) \\
0.00064(2) \\
0.0022(1) \\
\end{array}$ & $\begin{array}{l}0.977(4) \\
0.00054(2) \\
0.0020(1) \\
\end{array}$ \\
\hline 33000 & $\begin{array}{c}f_{1} \\
D_{1}\left(\mu m^{2} s^{-1}\right) \\
D_{2}\left(\mu m^{2} s^{-1}\right) \\
\end{array}$ & $\begin{array}{l}0.45(2) \\
0.00090(2) \\
0.00214(2) \\
\end{array}$ & $\begin{array}{l}0.94(1) \\
0.00105(2) \\
0.0027(2) \\
\end{array}$ & $\begin{array}{l}0.87(1) \\
0.00074(2) \\
0.00177(5) \\
\end{array}$ & $\begin{array}{l}0.88(1) \\
0.00060(2) \\
0.00152(3) \\
\end{array}$ & $\begin{array}{l}0.92(1) \\
0.00051(3) \\
0.00153(5) \\
\end{array}$ \\
\hline 66000 & $\begin{array}{c}f_{1} \\
D_{1}\left(\mu m^{2} s^{-1}\right) \\
D_{2}\left(\mu m^{2} s^{-1}\right)\end{array}$ & $\begin{array}{l}0.46(2) \\
0.00069(2) \\
0.00185(2)\end{array}$ & $\begin{array}{l}0.64(2) \\
0.00072(3) \\
0.00184(2)\end{array}$ & $\begin{array}{l}0.74(2) \\
0.00067(3) \\
0.00185(3)\end{array}$ & $\begin{array}{l}0.87(2) \\
0.00063(4) \\
0.00175(7)\end{array}$ & $\begin{array}{l}0.90(1) \\
0.00056(3) \\
0.00178(6)\end{array}$ \\
\hline
\end{tabular}


Table S2: The effective diffusion coefficient $D_{\text {eff }}\left(\mu m^{2} s^{-1}\right)=f_{1} D_{1}+f_{2} D_{2}$ as calculated by the fit parameters in the previous table. Values in parentheses indicate uncertainty in the last digit, calculated by propagation of error from fit parameters.

\begin{tabular}{|c|l|l|l|l|l|}
\hline & \multicolumn{5}{|c|}{$\mathrm{T}_{\mathrm{w}}(\mathrm{s})$} \\
\hline$\sigma_{\mathrm{g}}\left(\mu \mathrm{m}^{2} \mathrm{~s}^{-1}\right)$ & \multicolumn{1}{|c|}{0.2} & \multicolumn{1}{|c|}{0.3} & \multicolumn{1}{c|}{0.4} & \multicolumn{1}{c|}{0.5} & \multicolumn{1}{c|}{0.6} \\
\hline 0 & $0.00134(3)$ & $0.00122(6)$ & $0.00138(6)$ & $0.00171(6)$ & $0.00121(3)$ \\
830 & $0.00159(3)$ & $0.00146(8)$ & $0.001393(5)$ & $0.00155(8)$ & $0.00203(4)$ \\
2200 & $0.00189(7)$ & $0.00153(6)$ & $0.00158(7)$ & $0.00181(7)$ & $0.00159(2)$ \\
6600 & $0.00160(5)$ & $0.0022(2)$ & $0.0023(1)$ & $0.00175(9)$ & $0.0019(1)$ \\
8300 & $0.00180(7)$ & $0.0013(5)$ & $0.00116(5)$ & $0.00111(4)$ & $0.00114(6)$ \\
11000 & $0.00142(4)$ & $0.00126(4)$ & $0.00105(4)$ & $0.00095(3)$ & $0.00082(3)$ \\
16000 & $0.00144(6)$ & $0.00105(5)$ & $0.00080(2)$ & $0.00068(2)$ & $0.00058(2)$ \\
33000 & $0.00159(4)$ & $0.00115(5)$ & $0.00087(3)$ & $0.00071(3)$ & $0.00059(3)$ \\
66000 & $0.00132(4)$ & $0.00112(4)$ & $0.00097(5)$ & $0.00077(6)$ & $0.00068(3)$ \\
\hline
\end{tabular}




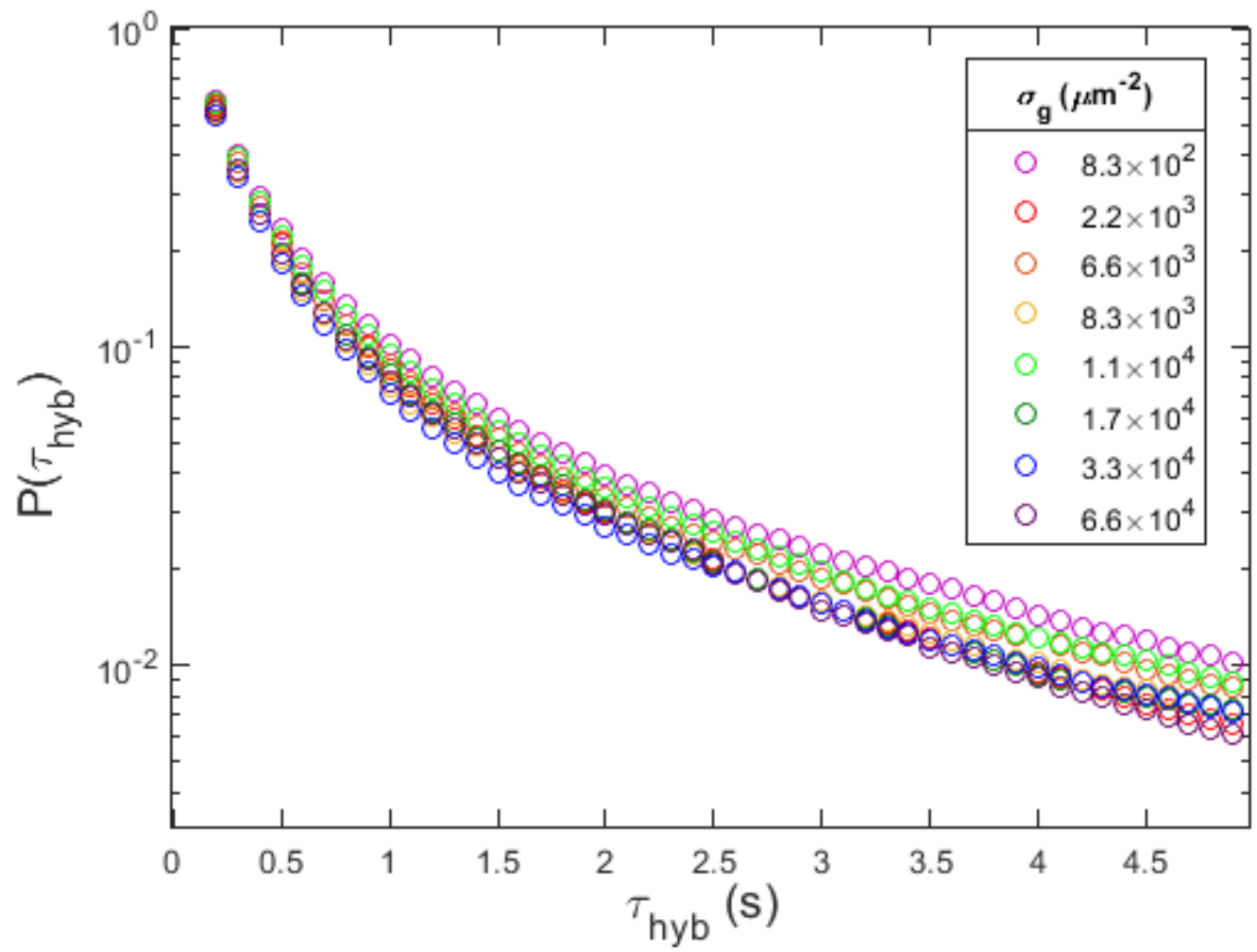

Figure S4: Complementary cumulative distribution for the association lifetime on all surfaces.

\section{Off-lattice Monte-Carlo simulations:}

We performed-off lattice Monte-Carlo simulation of molecular flights to compare with the flightlength distributions $\Phi(r)$ (Equation 5) in our experimental data. Each simulated molecule began a flight at the 3D location $(x, y, z)=(0,0,0)$, where the $\mathrm{z}$-direction refers to height above the surface. In each time-step the molecule moved in the $\mathrm{x}, \mathrm{y}$, and $\mathrm{z}$ direction sampled from the distribution

$$
P(x)=\left(\frac{1}{\sqrt{4 \pi D}}\right) e^{-\left(\frac{x^{2}}{4 D}\right)}
$$

with a diffusion coefficient $\mathrm{D}=1$ in arbitrary units. Since values of $\mathrm{z}$ less than 0 represented the solid interface, any step such that $\mathrm{z}<0$ was corrected such that $\mathrm{z}=0$. In time steps where $\mathrm{z}<1$, 
representing when the target molecule is within a "reaction region", the target has a probability $\mathrm{k}=0.8$ of adsorbing to the surface.

As analogs to surface probes, hemispherical surface features were also added in a square lattice pattern on the surface with variable nearest-neighbor spacing. When a target molecule was within a distance of 2 a.u. of the center of the hemispherical base, it had a probability $k=0.8$ of adsorbing to the surface. $10^{6}$ flights were simulated per surface, with a maximum of $10^{7}$ time steps. Surfaces included a surface with no surface features as well as surfaces with surface features with nearest-neighbor spacings of 10,5, and 3 a.u., corresponding with surface densities of $0.01,0.04$, and 0.111 respectively. The flight lengths were measured as $r=\sqrt{x^{2}+y^{2}}$ upon adsorption.

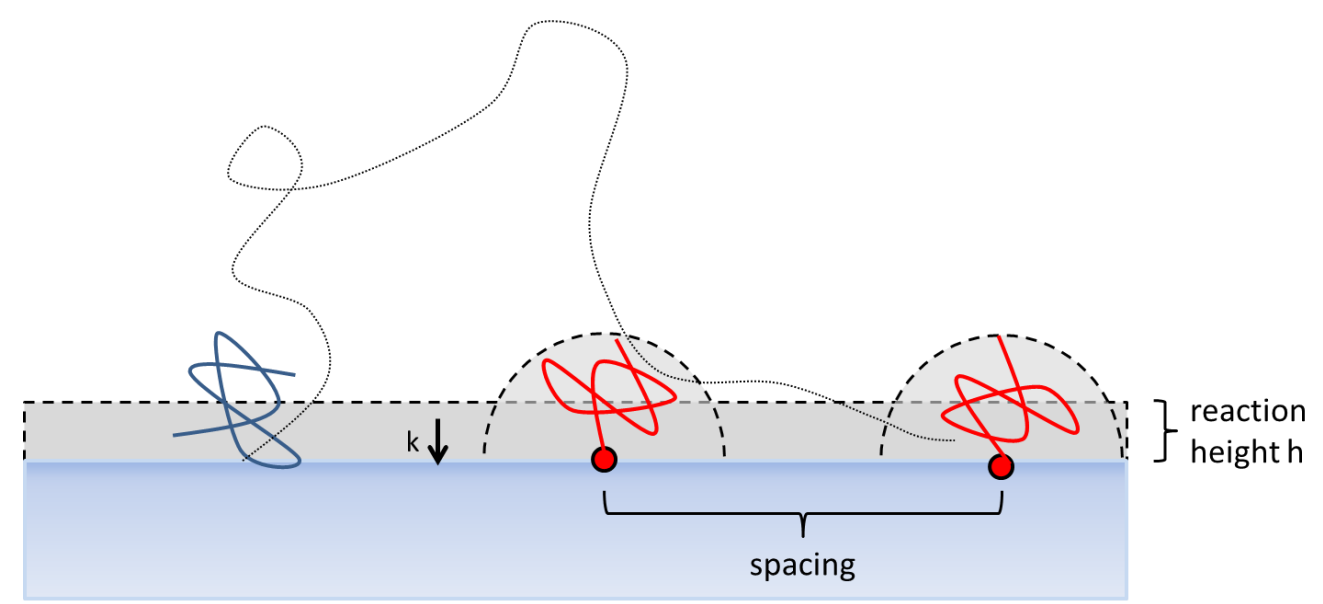

Figure S5: Schematic depicting the simulation described above. The reaction height $\mathrm{h}$ describes the region above the surface where a molecule has a probability $\mathrm{k}$ of adsorbing to the surface within a time-step. Hemispherical surface features of radius $2 \mathrm{~h}$, analogous to surface probes, are also present, and have square-lattice spacing across the surface where the spacing between features is varied between simulations. Diffusing target molecules in the simulation have a probability $\mathrm{k}$ of adsorbing to the surface if within the hemispherical region. 

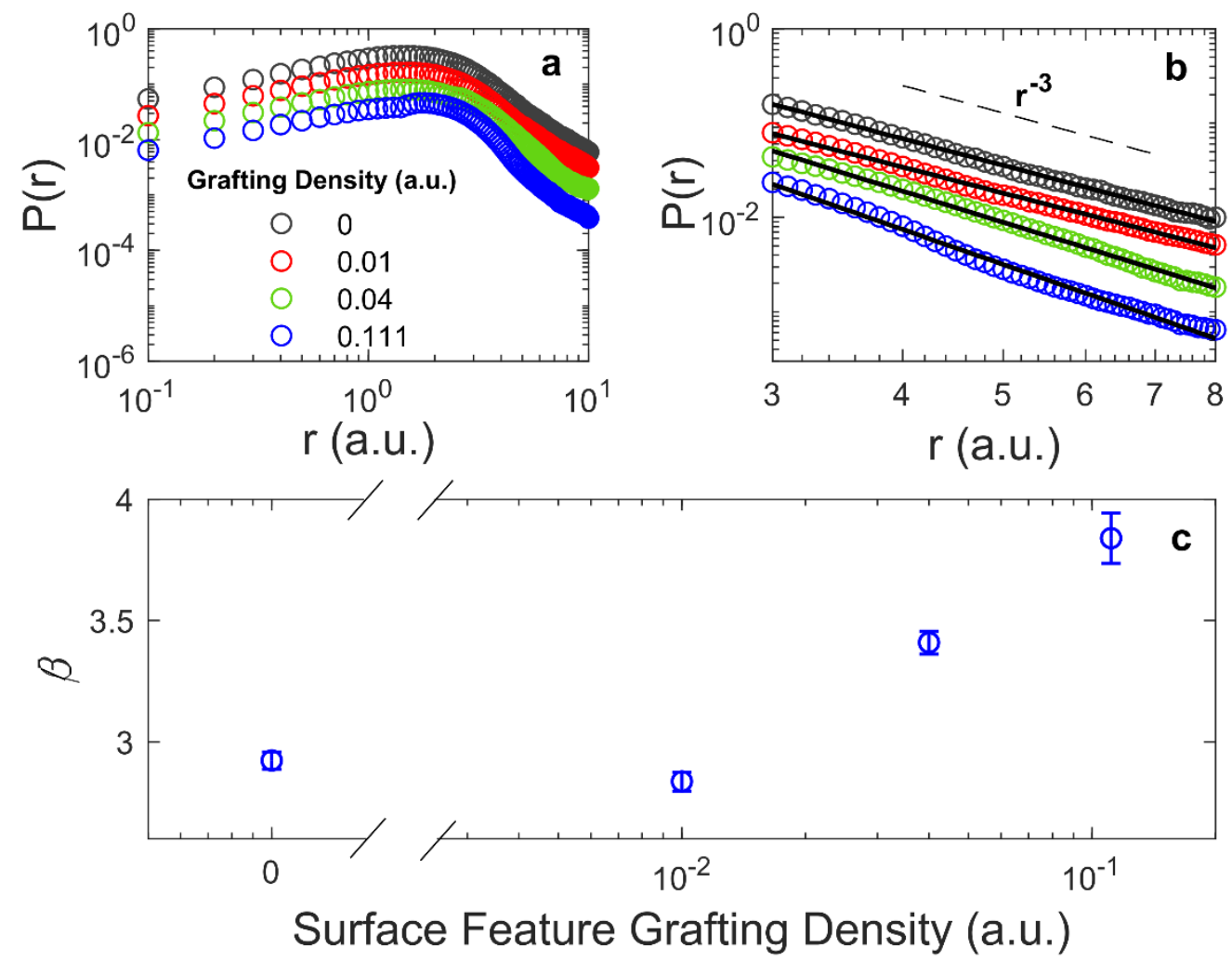

Figure S6: (a) Probability densities of flight lengths $r$ as a function of grafting density. (b) Probability densities of flight lengths $r$ in the decaying region beyond the distribution maxima. Black lines are power-law fits. (c) Exponential fit values for the decaying region.

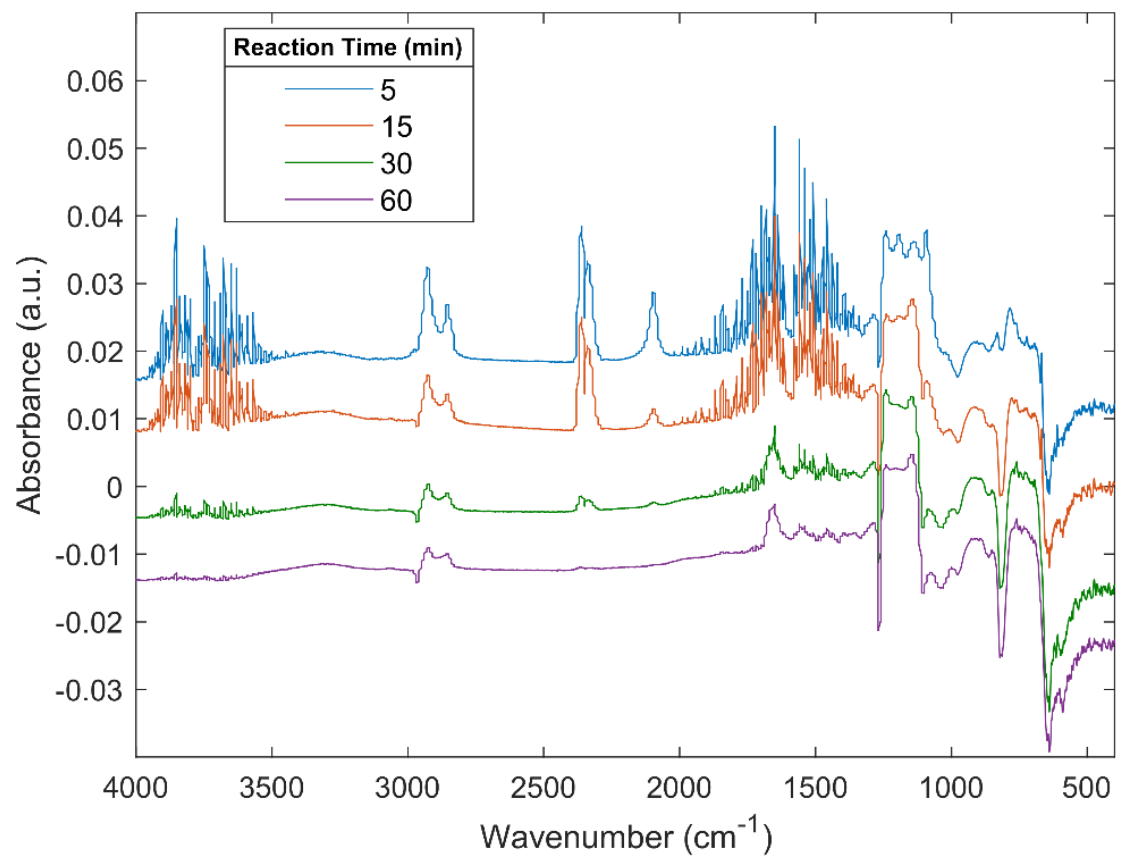

Figure S7: ATR-IR Spectra of azide-silane chemistry surfaces at various reaction times with DBCO-PEG. Azide peaks occur at $2098 \mathrm{~cm}^{-1}$. The peak at $1653 \mathrm{~cm}^{-1}$ was indexed to an amide carbonyl stretching mode. 


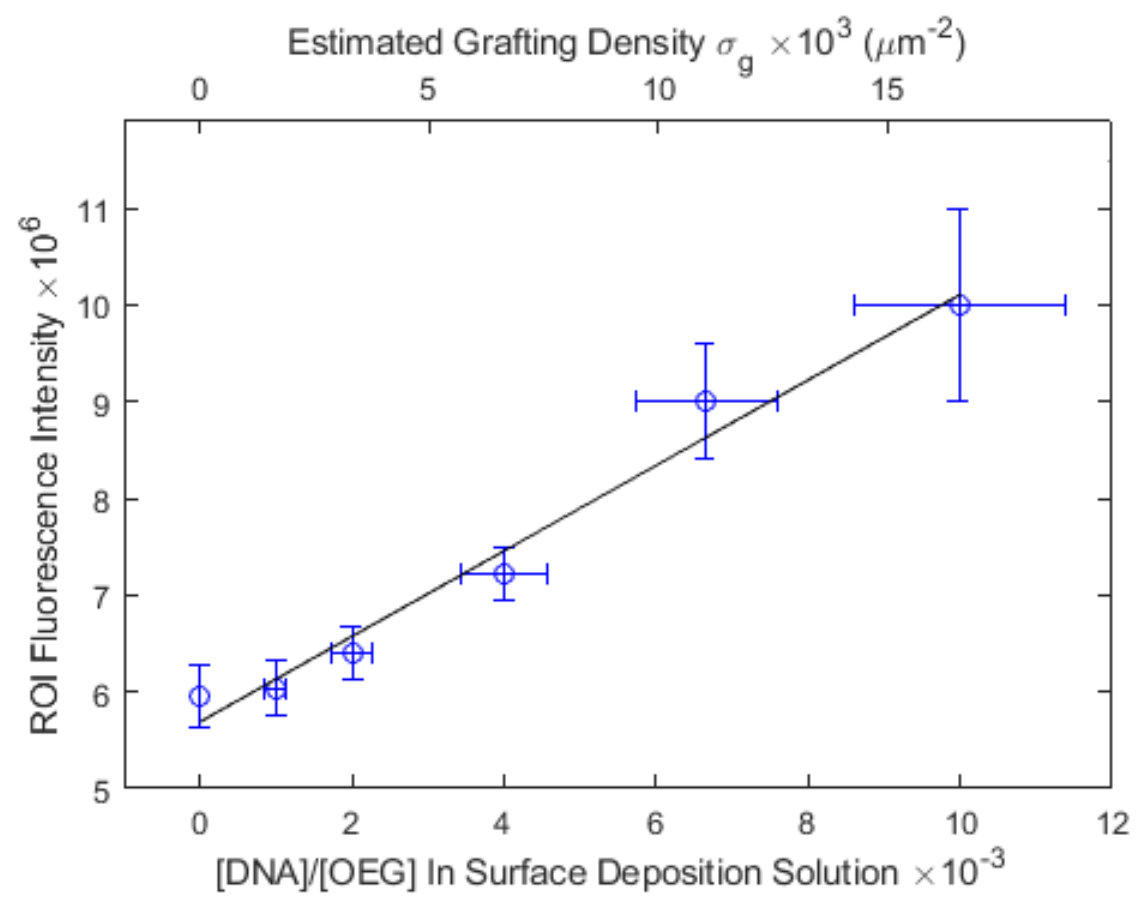

Figure S8: Integrated intensity of TIRFM region of interest (ROI) vs. the DNA to OEG concentration ratio in click deposition solution. The effective grafting density estimate $\sigma_{g}$ is calculated from this ratio is shown on the top axis. Vertical error bars correspond to standard error for 8 different regions per surface. Horizontal error bars are a result of the error in OEG grafting density $\sigma_{O E G}$.

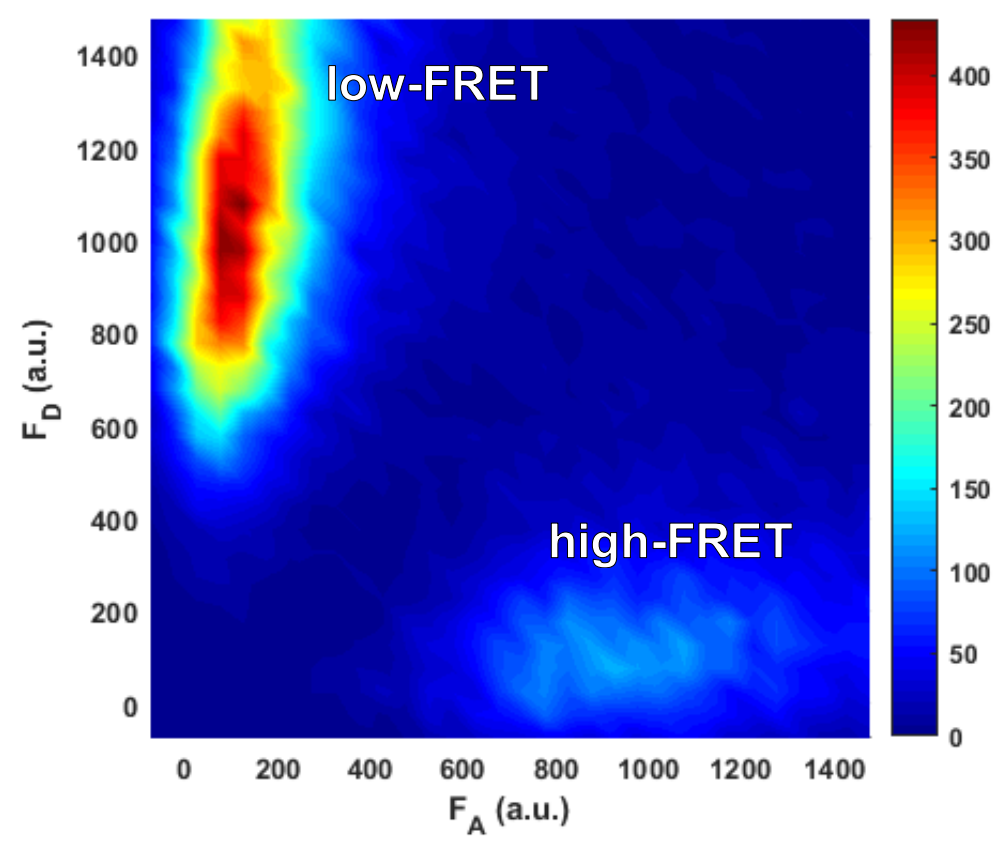

Figure S9: Heat map depicting the donor and acceptor intensity of each molecule in each frame. 